\title{
Anisodamine microcirulatory effects in septic shock: be aware of cardiac side effects
}

\author{
Patrick M. Honore ${ }^{1 *}$, Sebastien Redant ${ }^{1}$, Thierry Preseau ${ }^{2}$, Bogdan Vasile Cismas ${ }^{2}$, Keitiane Kaefer ${ }^{1}$, \\ Leonel Barreto Gutierrez ${ }^{1}$, Sami Anane ${ }^{1}$, Rachid Attou ${ }^{1}$, Andrea Gallerani ${ }^{1}$ and David De Bels ${ }^{1}$
}

Keywords: Anisodamine, Septic shock, Important cardiac side effects

With great interest, we read the recently published metaanalysis by $\mathrm{Yu}$ et al. stating that anisodamine was able to improve microcirculation in patients with septic shock, as supported by lower serum lactate levels and less vasopressor requirements in the treated group [1]. However, the mortality rate in the treated group was lower than that in the usual care group, suggesting that this non-significant finding might be attributable to the limited sample size of the current study [1]. The authors describe the potential beneficial effects of anisodamine in detail, but do not mention the numerous side effects. Anisodamine, a tropane alkaloid extracted from the root of Anisodus tanguticus (Maxim.) Pascher in the family Solanaceae, acts as non-specific muscarinic cholinoceptor antagonist competing with acetylcholine for binding to the muscarinic cholinergic receptor, blocking nerve impulses and physiological functions associated with cholinergic neurotransmission [2]. The autonomic receptors distributed in the cardiac, vascular, and airway smooth muscle are mainly muscarinic cholinoceptors [2]. Thus, the antimuscarinic activity of anisodamine can potentially lead to various physiological effects on the cardiorespiratory system [2] and early experimental and clinical studies have indeed reported that structurally-related tropane alkaloids (such as anisodamine, anisodine, scopolamine,

This comment refers to the article available online at https://doi.org/10.1186/ s13054-021-03774-4

*Correspondence: Patrick.Honore@CHU-Brugmann.be

${ }^{1}$ ICU Dept, Centre Hospitalier Universitaire Brugmann-Brugmann University Hospital, Place Van Gehuchtenplein, 4, 1020 Brussels, Belgium

Full list of author information is available at the end of the article and atropine) have potentially undesirable effects on the particularly the cardiovascular systems [2], such as tachycardia and induction of arrhythmia [2] especially atrial arrhythmia [3]. Anisodamine is also know to increase the heart oxygen consumption and can cause torsade de pointes by increasing the QT interval [4]. Anisodamine induces coronary blood vessel dilation, increasing coronary blood flow, while also possibly inducing simultaneous elevation of the ventricular fibrillation threshold [5].

\section{Authors' response}

Yuetian $\mathrm{Yu}^{3}$, Cheng Zhu ${ }^{4,5}$ and Zhongheng Zhang ${ }^{6}$

${ }^{3}$ Department of Critical Care Medicine, Ren Ji Hospital, School of

Medicine,

Shanghai Jiao Tong University, Shanghai, China

${ }^{4}$ Department of Disease Prevention and Control, Rui Jin Hospital, School

of Medicine, Shanghai Jiao Tong University, Shanghai, China

${ }^{5}$ Department of Emergency Medicine, Rui Jin Hospital, School of

Medicine,

Shanghai Jiao Tong University, Shanghai, China

${ }^{6}$ Department of Emergency Medicine, Sir Run Run Shaw Hospital,

Zhejiang

University School of Medicine, Hangzhou 310016, China

We thank Dr. Patrick Honoré and his colleagues for their comments and for the opportunity to further clarify some of the issues raised in our clinical trial [1]. Our study revealed that anisodamine treatment may decrease the serum lactate levels and the need for vasopressors in patients with septic shock. We fully agree that benefits and risks should be carefully weighed. Therefore, we have already pointed out in the protocol that major adverse original author(s) and the source, provide a link to the Creative Commons licence, and indicate if changes were made. The images or other third party material in this article are included in the article's Creative Commons licence, unless indicated otherwise in a credit line to the material. If material is not included in the article's Creative Commons licence and your intended use is not permitted by statutory regulation or exceeds the permitted use, you will need to obtain permission directly from the copyright holder. To view a copy of this licence, visit http://creativecommons.org/licenses/by/4.0/. The Creative Commons Public Domain Dedication waiver (http://creativeco mmons.org/publicdomain/zero/1.0/) applies to the data made available in this article, unless otherwise stated in a credit line to the data. 
events related to anisodamine administration (bowel obstruction, urine retention, tachy arrythmias) should be pre-specified in the case report form and should be screened daily by the investigators [6].

Arrhythmia can be noticed easily, which include atrial fibrillation, ventricular tachycardia and even ventricular fibrillation. In a multicenter, randomized trial, it was indicated that arrhythmia was recognized in 207 (24.1\%) shock patients with dopamine treatment and 102 $(12.4 \%)$ shock patients under norepinephrine treatment $(p<0.001)$ [7]. We acknowledge the fact that the antimuscarinic activity of anisodamine can potentially lead to various physiological effects on the cardiorespiratory system, especially atrial arrhythmias [3]. However, it is difficult to ascribe the side effects to anisodamine administration or the vasopressor treatment.

Our study included 355 patients with septic shock, including $22(6 \%)$ with heart failure (11 in each group). Data of these patients was re-analyzed and it showed that atrial fibrillation was recognized in 4 patients in the anisodamine group and 3 patients in the control group. For the entire population, arrhythmias were found in 15 (8.3\%) patients in the anisodamine group and 18 (10.3\%) patients in the control group $(p=0.627)$ during the treatment, which is lower than in the previous study [7]. The side effects of arrhythmias cannot be ignored due to the anisodamine treatment, especially for those with cardiogenic shock and further study is needed to clarify the causality.

\section{Acknowledgements}

None.

\section{Authors' contributions}

PMH, SM, SL, DDB designed the paper. All authors participated in drafting and reviewing. All authors read and approved the final version of the manuscript.

\section{Funding}

None.

Availability of data and materials

Not applicable.

\section{Declarations}

Ethics approval and consent to participate

Not applicable.

\section{Consent for publication}

Not applicable.

\section{Competing interests}

The authors declare to have no competing interests.

\section{Author details}

${ }^{1}$ ICU Dept, Centre Hospitalier Universitaire Brugmann-Brugmann University Hospital, Place Van Gehuchtenplein, 4, 1020 Brussels, Belgium. ${ }^{2}$ ED Dept, Centre Hospitalier Universitaire Brugmann, Brussels, Belgium. ${ }^{3}$ Department of Critical Care Medicine, Ren Ji Hospital, School of Medicine, Shanghai Jiao Tong University, Shanghai, China. ${ }^{4}$ Department of Disease Prevention and Control, Rui Jin Hospital, School of Medicine, Shanghai Jiao Tong University, Shanghai, China. ${ }^{5}$ Department of Emergency Medicine, Rui Jin Hospital, School of Medicine, Shanghai Jiao Tong University, Shanghai, China. ${ }^{6}$ Department of Emergency Medicine, Sir Run Run Shaw Hospital, Zhejiang University School of Medicine, Hangzhou 310016, China.

Received: 20 November 2021 Accepted: 27 November 2021

Published online: 16 December 2021

\section{References}

1. Yu Y, Zhu C, Hong Y, et al. Effectiveness of anisodamine for the treatment of critically ill patients with septic shock: a multicentre randomized controlled trial. Crit Care. 2021;25(1):349. https://doi.org/10.1186/s13054021-03774-4 (PMID:34579741; PMCID:PMC8474812).

2. Chen DT, Lin CS, Gu MN, et al. Effects of penehyclidine hydrochloride and anisodamine on acute kidney injury induced by two-hit rats. Afr J Pharm Pharmacol. 2012;6(26):1949-57.

3. Zhu CP, Jiang F, Wang RQ, et al. Comparison of efficacy and safety of hyoscine butylbromide versus anisodamine for acute gastric or intestinal spasm-like pain: a randomized, double-blinded, multicenter Phase III trial. J Dig Dis. 2017;18(8):453-60. https://doi.org/10.1111/1751-2980.12504 (PMID: 28677349).

4. Andersson KE, Campeau L, Olshansky B. Cardiac effects of muscarinic receptor antagonists used for voiding dysfunction. $\mathrm{Br} J \mathrm{Clin}$ Pharmacol. 2011;72(2):186-96. https://doi.org/10.1111/j.1365-2125.2010.03813.x (PMID:21595741; PMCID:PMC3162648).

5. Jianping $H$, Yaochun $L$, Hongying $L$, et al. Effects of anisodamine on coronary blood flow and ventricular fibrillaton threshold in isolated rabbit heart. https://en.cnki.com.cn/Article_en/CJFDTOTAL-MAKE701.013.htm.

6. Zhang Z, Zhou J, Shang Y, Wang $X$, Yin R, Zhu Z, et al. Effectiveness of anisodamine for the treatment of critically ill patients with septic shock (ACldoSIS study): study protocol for randomized controlled trial. Ann Transl Med. 2015;3(17):246.

7. De Backer D, Biston P, Devriendt J, Madl C, Chochrad D, Aldecoa C, et al. Comparison of dopamine and norepinephrine in the treatment of shock. N Engl J Med. 2010;362(9):779-89.

\section{Publisher's Note}

Springer Nature remains neutral with regard to jurisdictional claims in published maps and institutional affiliations.

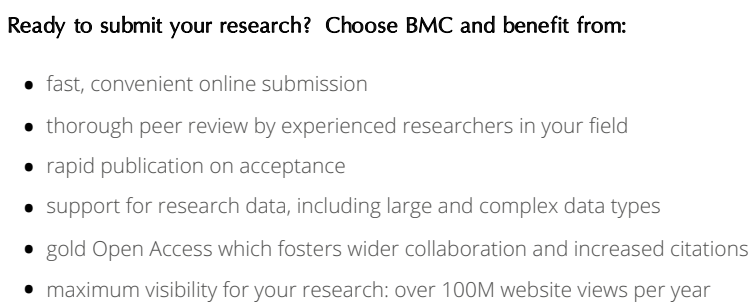

At BMC, research is always in progress.

Learn more biomedcentral.com/submissions 